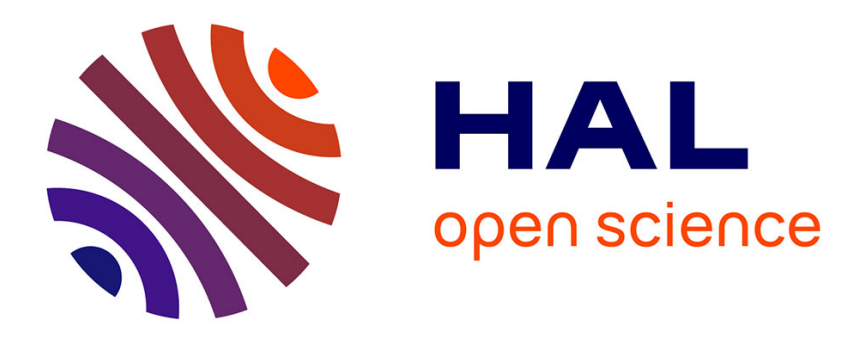

\title{
On the molecular mechanisms of the acid-induced dissociation of hydroxy-apatite in water
}

\author{
Oliver Hochrein, Dirk Zahn
}

\section{To cite this version:}

Oliver Hochrein, Dirk Zahn. On the molecular mechanisms of the acid-induced dissociation of hydroxyapatite in water. Journal of Molecular Modeling, 2010, 17 (6), pp.1525-1528. 10.1007/s00894-0100855-9 . hal-00628284

\section{HAL Id: hal-00628284 \\ https://hal.science/hal-00628284}

Submitted on 1 Oct 2011

HAL is a multi-disciplinary open access archive for the deposit and dissemination of scientific research documents, whether they are published or not. The documents may come from teaching and research institutions in France or abroad, or from public or private research centers.
L'archive ouverte pluridisciplinaire HAL, est destinée au dépôt et à la diffusion de documents scientifiques de niveau recherche, publiés ou non, émanant des établissements d'enseignement et de recherche français ou étrangers, des laboratoires publics ou privés. 


\section{Editorial Manager(tm) for Journal of Molecular Modeling Manuscript Draft}

\section{Manuscript Number: JMM01588R1}

Title: On the Molecular Mechanisms of the acid-induced Dissociation of Hydroxy-Apatite in Water

Article Type: Original paper

Keywords: apatite dissociation, caries, molecular dynamics simulations

Corresponding Author: Prof. Dr. Dirk Zahn,

Corresponding Author's Institution: Lehrstuhl für Theoretische Chemie / Computer-Chemie-Centrum

First Author: Oliver Hochrein

Order of Authors: Oliver Hochrein; Dirk Zahn

Abstract: The enamel/saliva interface is mimicked by the comparably much simpler model of (001) surfaces of hydroxy-apatite ( $\mathrm{Ca} 10(\mathrm{PO} 4) 6(\mathrm{OH}) 2$ ) in contact with aqueous solution. At neutral $\mathrm{pH}$, the dissociation of ions is penalized by more than $150 \mathrm{~kJ} / \mathrm{mol}$ giving rise to very stable apatite-water interfaces. This picture changes drastically with decreasing $\mathrm{pH}$, as the protonation of phosphate and hydroxide ions lowers the free energy of calcium ions dissociation. Our simulations suggest the mechanism of acid-induced apatite decomposition to i) require a considerable degree of protonation of the apatite surface. The first ion dissociation step ii) involves calcium ions which electrostatic binding has been locally destabilized through phosphate and hydroxide protonation. The depletion of calcium ions embedding the anions then allows iii) the dissociation of the anionic species. Along this line, the protective role of fluoride in caries prevention is related to the stabilization of the calcium triangles embedding the $\mathrm{OH}-/ \mathrm{F}$ - ions.

Response to Reviewers:

The addressed typos and grammatical errors were corrected. Throughout the manuscript we now use the more precise notation $\mathrm{Ca} 2+$ or calcium ion. 


\title{
On the molecular mechanisms of the acid-induced dissociation of hydroxy-apatite in water
}

Received: 30.07.2010 / Accepted: 08.09.2010

Oliver Hochrein and Dirk Zahn ${ }^{\bowtie}$

Lehrstuhl für Theoretische Chemie / Computer Chemie Centrum; Friedrich-Alexander Universität Erlangen-Nürnberg; Nägelsbachstraße 25, 91052 Erlangen, Germany

${ }^{\square}$ Email: dirk.zahn@chemie.uni-erlangen.de

\begin{abstract}
The enamel/saliva interface is mimicked by the comparably much simpler model of (001) surfaces of hydroxy-apatite $\left(\mathrm{Ca}_{10}\left(\mathrm{PO}_{4}\right)_{6}(\mathrm{OH})_{2}\right)$ in contact with aqueous solution. At neutral $\mathrm{pH}$, the dissociation of ions is penalized by more than $150 \mathrm{~kJ} \mathrm{~mol}^{-1}$ giving rise to very stable apatite-water interfaces. This picture changes drastically with decreasing $\mathrm{pH}$, as the protonation of phosphate and hydroxide ions lowers the free energy of calcium ions dissociation. Our simulations suggest the mechanism of acid-induced apatite decomposition to i) require a considerable degree of protonation of the apatite surface. The first ion dissociation step ii) involves calcium ions which electrostatic binding has been locally destabilized through phosphate and hydroxide protonation. The depletion of calcium ions embedding the anions then allows iii) the dissociation of the anionic species. Along this line, the protective role of fluoride in caries prevention is related to the stabilization of the calcium triangles embedding the $\mathrm{OH}^{-} / \mathrm{F}^{-}$ions.
\end{abstract}

Keywords Apatite dissociation $\cdot$ Caries $\cdot$ Molecular dynamics simulations 


\section{Introduction}

The enamel of human teeth predominantly consists of hydroxy-apatite (besides about $3 \mathrm{wt} \%$ proteins and lipoproteins and $2 \mathrm{wt} \%$ water). Therein, highly ordered crystal bundles of apatite-needles are arranged hierarchically in so-called enamel prisms. These prisms exhibit a parallel orientation to each other, and the surface of teeth is formed by the (001) basal planes [1]. It was shown from both experiments and calculations that the (001) planes of apatite are the most stable surfaces/interfaces with respect to both vacuum and aqueous phases [2]. Indeed, (001) surfaces are the predominant form of interfaces of teeth to the saliva [3].

While enamel is one of the hardest tissue materials known, it is quite vulnerable to aqueous solutions of low $\mathrm{pH}$. Enamel damage via acid-induced apatite dissociation represents an every-day process, being part of the caries disease. The detailed mechanisms of caries are still not fully understood. Even for the simpler process of the acid-induced dissolution of nonbiogenic hydroxy-apatite no unique model is accepted. A common feature of the variety of mechanisms discussed so far is given by the protonation of the hydroxyl and phosphate ions of the apatite crystal surface as the initial step of the apatite decomposition [4].

Based a recent theoretical study in which we elucidated the hydration of different types of (001) surfaces of hydroxy-apatite [5], here we employ molecular dynamics simulations to explore the first steps of apatite dissociation. Within a systematic approach, ion dissociation is investigated for all accessible ionic species of the apatite surface. Along this line, the effect of the protonation of interfacial hydroxyl and phosphate ions is explored.

\section{Simulation details}

Our simulation model was chosen from a recent study dedicated to different types of (001) interfaces of apatite and water [5]. Using periodic boundary conditions, a sandwich structure of apatite slabs and water was obtained. Therein, apatite is mimicked by a block of $3 \times 3 \times 3$ unit cells of monoclinic hydroxy-apatite [6]. By simple cutting of the unit cell (Fig. 1), the (001) and $(00 \overline{1})$ surfaces of the apatite slices differ with respect to the occupation of the $\mathrm{Ca} 2$ ion positions. This is both counter-intuitive and energetically unfavorable. Here we use the preferred interface type for which $50 \%$ of the $\mathrm{Ca} 2$ positions are occupied at both faces of the 
apatite slab [5]. The latter is hydrated by 2394 water molecules giving rise to bulk water phases of about $2.5 \mathrm{~nm}$ thickness.

Empirical interaction potentials were adopted from earlier studies of apatite/calcium phosphate in aqueous solution $[5,7]$. Ewald summation is used to provide a proper account of the long-range Coulomb interactions. Within the constant-pressure constant-temperature ensemble, ambient conditions are applied. Therein, an anisotropic barostat is used in order to allow cell shape variations [8]. For the molecular dynamics simulations a time step of $2 \mathrm{fs}$ was found to be appropriate.

For the potential of mean force calculations individual ions were separated from the apatite surface using the ion-surface distance as a model reaction coordinate. Probing distances of roughly 0 to $10 \AA$ in intervals of $0.125 \AA$, the average constraint force is sampled from molecular dynamics simulation. For each constraint scenario, a few picoseconds of relaxation and sampling periods of about 25 ps were found to be adequate. Throughout this work we applied the constraint forces to individual ions, only. It should be pointed out, that this does rule out the separation of groups of ions from the apatite surface. Indeed, all other degrees of freedom are allowed to relax during the constant-temperature, constant-pressure molecular dynamics simulations.

\section{Results}

As a starting point to exploring the dissociation of the (001) apatite interface, we investigated the separation of individual hydroxide, phosphate and calcium ions (Ca1 and $\mathrm{Ca} 2$ types, see also Fig. 1) from the crystal surface. Unsurprisingly, the required free energy is rather large, taking a minimum of about $150 \mathrm{~kJ} \mathrm{~mol}^{-1}$ for the Ca1-type calcium ions. The strong endothermic nature of these dissociation steps reflects the extremely low solubility of apatite in aqueous solution of neutral and basic $\mathrm{pH}$.

It is reasonable to expect the dissociation of apatite anions to be supported by hydroxide/phosphate protonation prior to the separation from the crystal surface. Unlike the hydroxide ions, only the oxygen atoms of the phosphate ions were found to act as hydrogen bond acceptors with respect to the aqueous solution. Thus only this ionic species appears as a first candidate to protonation from solution. Fig. 2 illustrates a protonated phosphate ion at the 
apatite-water interface after structural relaxation. The relaxed orientation of the hydrogen phosphate ions corresponds to a hydrogen bonded $\left[\mathrm{HO} * \mathrm{HPO}_{4}\right]^{3-}$ complex indicating the possibility of $\mathrm{OH}^{-}$protonation by the hydrogen phosphate ion. Thus, at the interface of apatite and acidic aqueous solution, we suggest hydroxide ion protonation to occur indirectly from via phosphate protonation.

In the course of proton uptake, the ionic charge is reduced and the Coulomb attraction to the crystal surface is lowered considerably. This scenario in principle holds both of the two anionic species. However, the phosphate ions exhibit only one oxygen atom that is accessible to protonation from the aqueous solution and we can hence only expect the formation of $\mathrm{HPO}_{4}{ }^{2-}$ ions, whilst $\mathrm{H}_{2} \mathrm{PO}_{4}{ }^{-}$will only be formed at later stages of decomposing the apatite surface. Thus for the phosphate ions only a limited reduction of the Coulomb attraction to the crystal is possible. On the other hand, the charge of the hydroxide ions may be completely neutralized by protonation.

To explore the effect of protonation on anion dissociation we performed constraint molecular dynamics simulations and calculated the potential of mean force as a function of the ionapatite surface distance. This was done for $\mathrm{OH}^{-}$separation and $\mathrm{OH}^{-}$protonation and subsequent $\mathrm{H}_{2} \mathrm{O}$ separation from the interface. The energy profiles (Fig. 3) indicate a considerable lowering of the required energy, yet clearly show an endothermic character for both dissociation events. The phosphate ions, which center of mass lies below that of the hydroxide ions, are even stronger embedded (by calcium ions) into the apatite surface. Thus dissociation should be even more endothermic than observed for hydroxide ions.

As far as the initial step of ion dissociation is concerned, we hence conclude the stability of the anion sites of the apatite-water interface. In what follows, we therefore explore the separation of calcium ions from the apatite surface. $\mathrm{Ca}^{2+}$ dissociation must be investigated for two separate cases, the $\mathrm{Ca} 1$ and the $\mathrm{Ca} 2$ type of calcium ion positions. The $\mathrm{Ca} 1$ species is coordinated by phosphate ions, only. We thus explored $\mathrm{Ca}^{2+}$ separation from the apatite surface from the Ca1 position as a function of phosphate protonation in the first neighborhood of the calcium ion under investigation. The corresponding energy profiles (Fig. 3a) indicate the dissociation process to be endothermic up to two-fold protonation, whilst coordination by three hydrogen phosphate ions provides sufficient destabilization to make $\mathrm{Ca}^{2+}$ dissociation exothermic. 
In analogy to calcium ion separation from the Ca1 type lattice (surface) position, we then explored $\mathrm{Ca}^{2+}$ displacement from the $\mathrm{Ca} 2$ type position. The $\mathrm{Ca} 2$ ions form a triangle embedding a hydroxide ion and are coordinated by three phosphate ions in the nearest neighborhood (see also Fig. 2). Strikingly, all four anions must be protonated to allow the dissociation of calcium ion from a Ca2 site (Fig. 4b). Thus a local excess charge of +4 must be created to cause exothermic $\mathrm{Ca}^{2+}$ displacement.

An important issue of such local charge accumulation is given by the proton affinities of the corresponding anions. Even at neutral $\mathrm{pH}$, the protonation of single $\mathrm{PO}_{4}{ }^{3-}$ and $\mathrm{OH}^{-}$ions of the apatite surface is intuitive. The collective protonation of all four anions coordinating a $\mathrm{Ca} 2$ type calcium ion however requires acidic conditions.

It should also be pointed out that the protonation of the hydroxide ion is a crucial prerequisite to $\mathrm{Ca} 2$ dissociation. Thus replacing $\mathrm{OH}^{-}$by $\mathrm{F}^{-}$ion at the apatite surface (e.g. by application of fluorinated tooth paste) helps to avoid the dissociation of $\mathrm{Ca} 2$ type ions. Fluoride ions exhibit much lower proton affinities ( $\mathrm{pKB}=10.8$, weak base) compared to hydroxide ( $\mathrm{pkB}=0$, strong base). In contrast to hydroxide ion protonation, HF formation is much less feasible and so is the formation of an excess +4 charge in the neighborhood of $\mathrm{Ca} 2$ type calcium ions. While fluoride incorporation into hydroxy-apatite is also known to improve the mechanical hardness, the protective role of fluoride for caries prevention may therefore be attributed to chemical considerations: $\mathrm{Ca}_{3} \mathrm{~F}$ units represent a particularly stable motive of apatite with respect to ion dissociation into solution.

\section{Conclusions}

On the basis of our simulations we can hence suggest a conclusive mechanism of the first step of hydroxyapatite dissociation in aqueous solution. Acidic conditions strongly promote the dissolution process, as a central prerequisite to ion dissociation is given by a considerable degree of protonation of the apatite surface. Focusing on the ideal single crystalline (001) surface of apatite, the hydroxide and phosphate ions were found to be rather inert to dissociation. This may be attributed to the embedding calcium ions which must be removed from the apatite surface prior to anion dissociation. The separation of calcium ions requires strong repulsive Coulomb interactions which imply the accumulation of an excess +3 and +4 
charge in the nearest neighborhood of $\mathrm{Ca} 1$ and $\mathrm{Ca} 2$ type calcium ions, respectively. For the $\mathrm{Ca} 2$ type ions, such coordination may be suppressed by replacing the neighboring hydroxide ion by a fluoride ion. Thus, the apatite surface may be stabilized by the formation of $\mathrm{Ca}_{3} \mathrm{~F}$ motives. Therein, each of the $\mathrm{Ca} 2$ type calcium ions is protected with respect to ion dissociation into solution.

\section{Acknowledgments}

The authors wish to acknowledge R. Kniep for fruitful discussions. 


\section{References}

1. Busch S, Schwarz U, Kniep R (2001) Chem Mater 13:3260-3271

2. Mkhonta D, de Leeuw N (2002) J Mater Chem 12:2633-2642

3. Radlanski RJ, Seidl W, Steding G, Jäger A (1998) Anat Anz Jena 168:405-412

4. Dorozhkin SV (2002) Prog Cryst Growth Ch 44:45-61

5. Zahn D, Hochrein O (2003) Phys Chem Chem Phys 5 18:4004-4007

6. Elliot JC, Mackie PE, Young RA (1973) Science 180:1055-1057

7. Zahn DZ (2004) Z Anorg Allg Chem 630:1507-1511

8. Melochionna S, Cicotti G, Holian BL (1993) Molec Phys 78:533-535 


\section{Figure captions}

Fig. 1 Unit cell of hydroxyapatite (monoclinic modification). The overall model system comprises a sandwich of $3 \times 3 \times 3$ unit cells of hydroxy-apatite which $(001) /(00 \overline{1})$ surfaces are in contact with water. Periodic boundaries are applied in all directions. Along the c direction the water phase extends over about $2.5 \mathrm{~nm}$ which was shown to be sufficient to allow bulk water phase of more than $1 \mathrm{~nm}$ thickness [5]

Fig. 2 Close-up of a of the apatite-water interface (solvent not shown) highlighting the local neighborhood of a hydroxide ion at the crystal surface. The hydroxide ions are embedded by triangles of calcium ions ( $\mathrm{Ca} 2$ positions, see also Fig. 1). Next to the calcium triangle, a single phosphate ion was protonated. The relaxed orientation of the hydrogen phosphate ions corresponds to a hydrogen bonded $\left[\mathrm{HO} \cdot \mathrm{HPO}_{4}\right]^{3-}$ complex. While not directly accessible to hydrogen bonding with the solvent, the $\mathrm{OH}^{-}$ions can hence accept a proton indirectly via phosphate protonation

Fig. 3 Potential of mean force curves for anion dissociation. The intact matrix of calcium ions at the apatite surface prevents anion dissociation. This also holds for protonated anions. Only energy profiles for hydroxide ions and water molecules are shown here

Fig. 4 (a) Dissociation of the Cal calcium ion species. The protonation of 3 adjacent phosphate ions leads to sufficient Coulomb repulsion to allow $\mathrm{Ca}^{2+}$ dissociation into the aqueous solution

(b) Dissociation of the $\mathrm{Ca} 2$ calcium ion species. The protonation of 3 adjacent phosphate ions and the hydroxide ion is required to provide sufficient Coulomb repulsion to allow $\mathrm{Ca}^{2+}$ dissociation into the aqueous solution. Replacing the $\mathrm{OH}^{-}$ ions at the apatite surface by $\mathrm{F}^{-}$ions should affect the energy profiles for $\mathrm{Ca}^{2+}$ dissociation only marginally. A considerable difference of fluor- and hydroxyapatite is however given by the much lower likeliness of fluoride protonation in contrast to the hydroxide ions 
Click here to download high resolution image

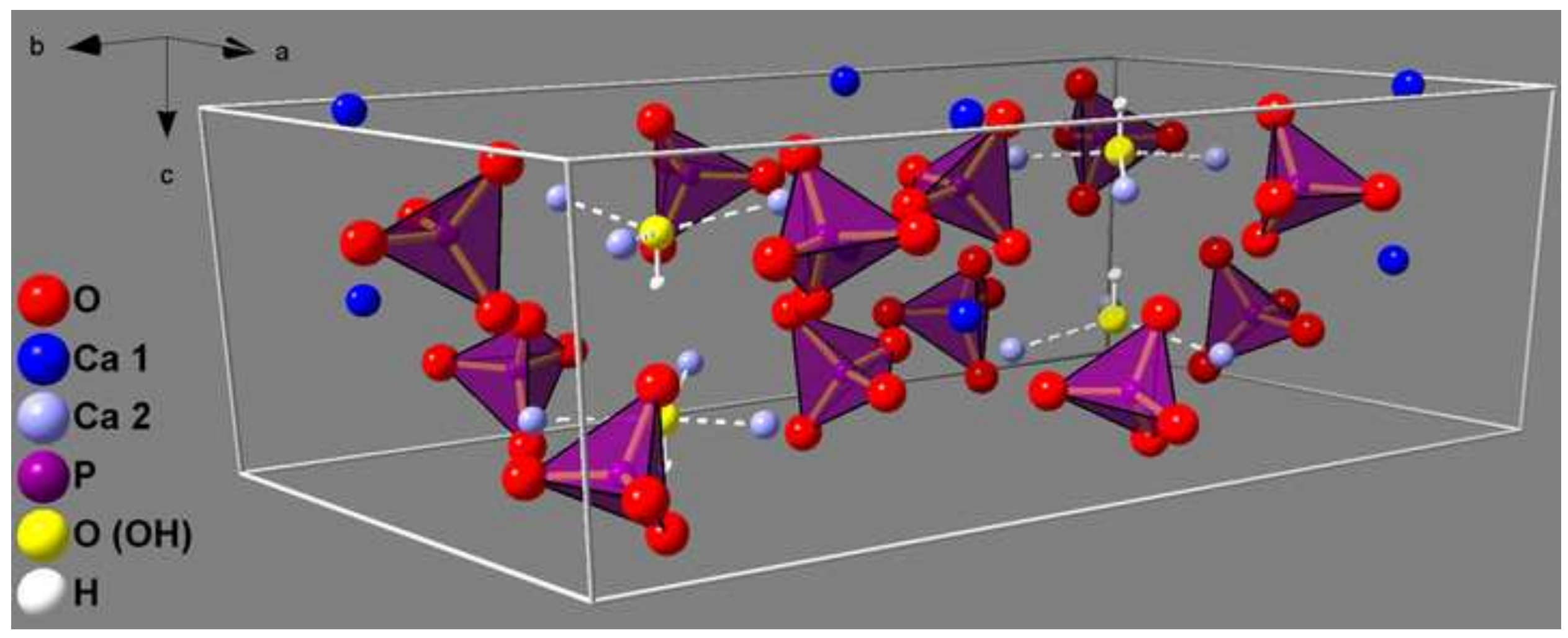




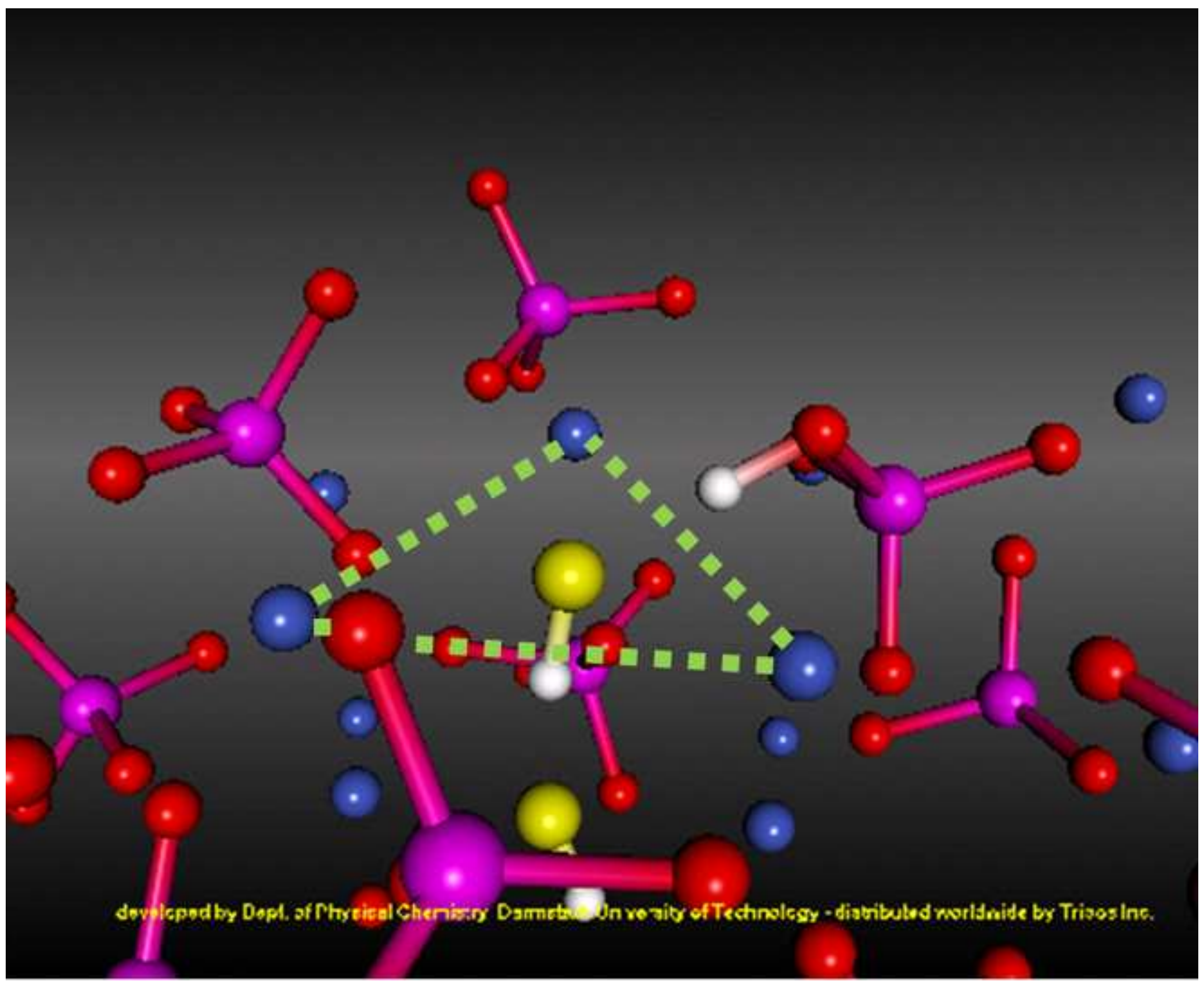


Figure 3

Click here to download line figure: Fig3.doc

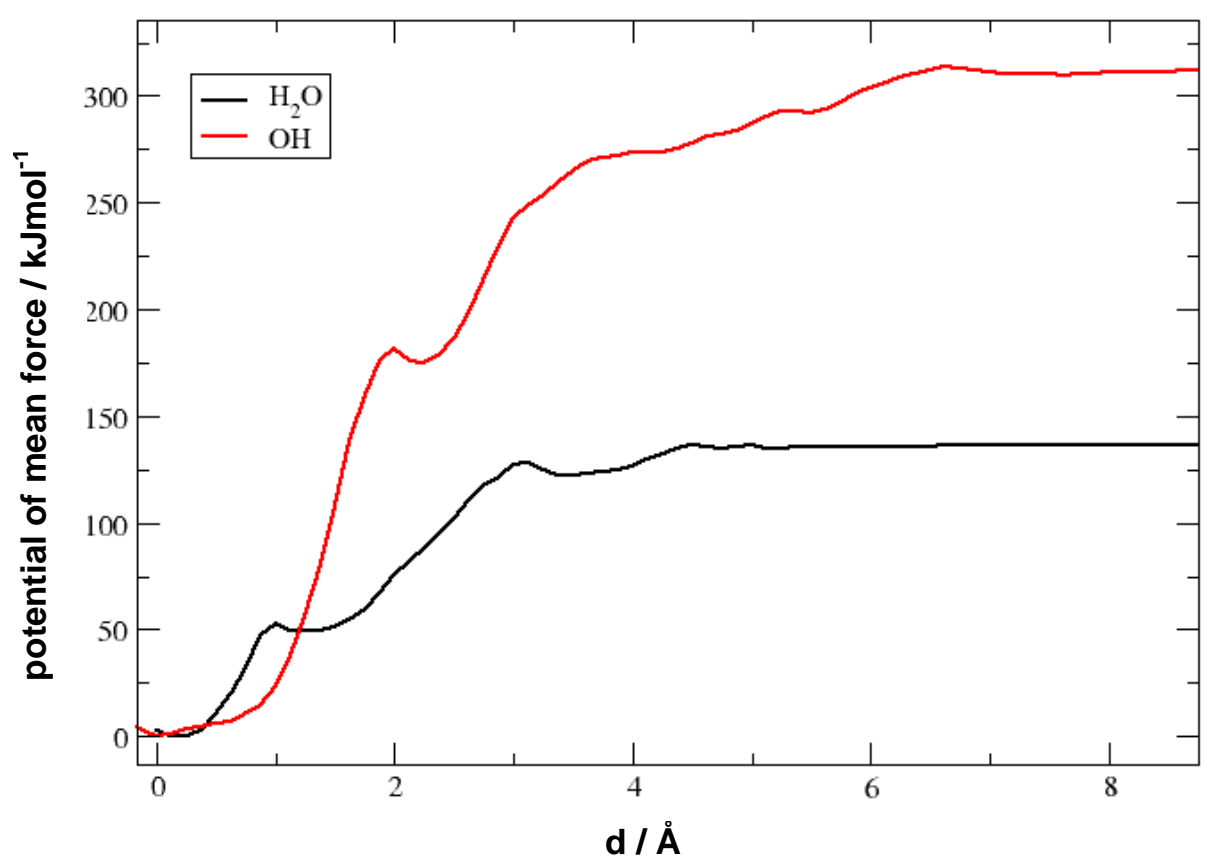


Figure 4a

Click here to download line figure: Fig4a.doc

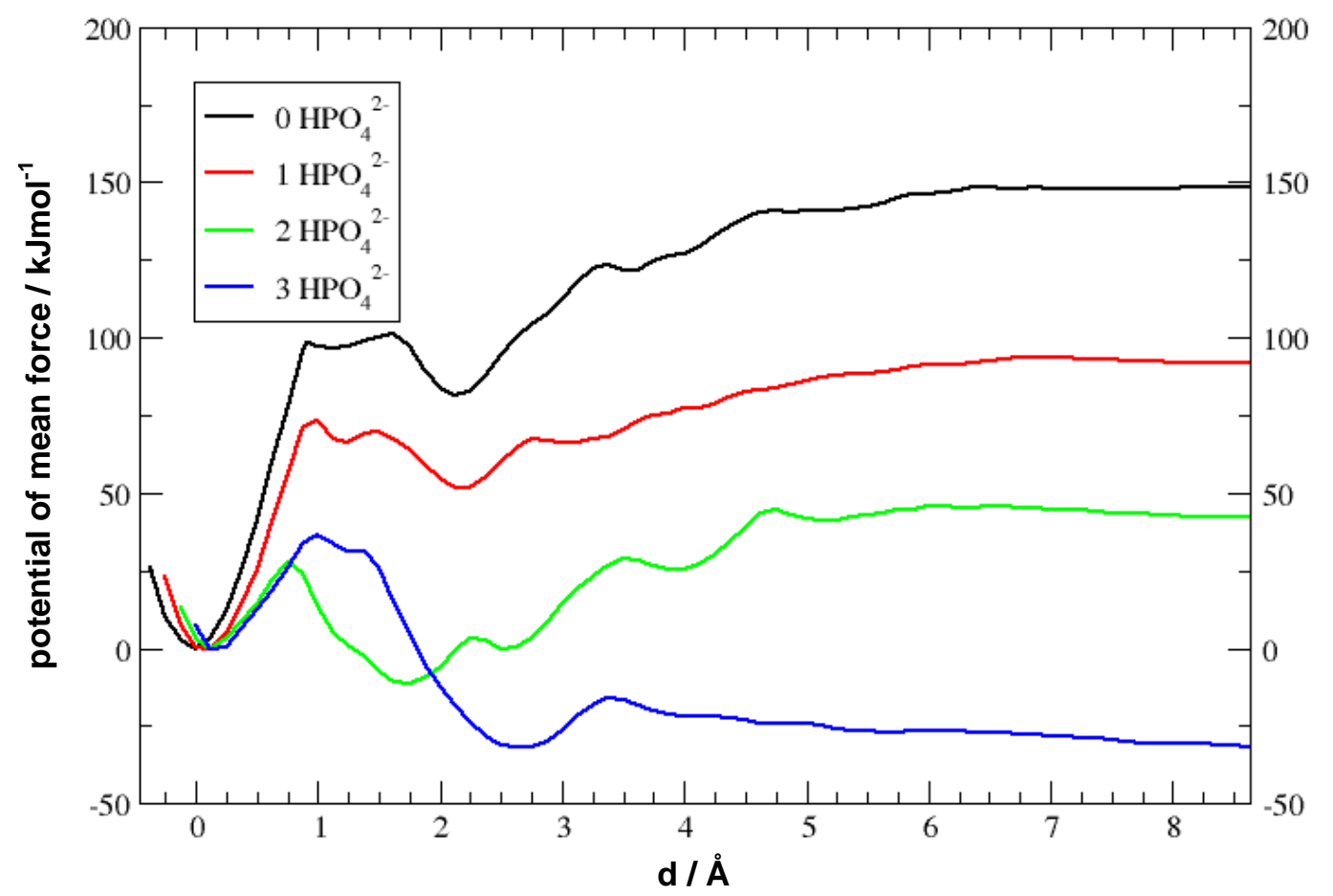


Figure 4b

Click here to download line figure: Fig4b.doc

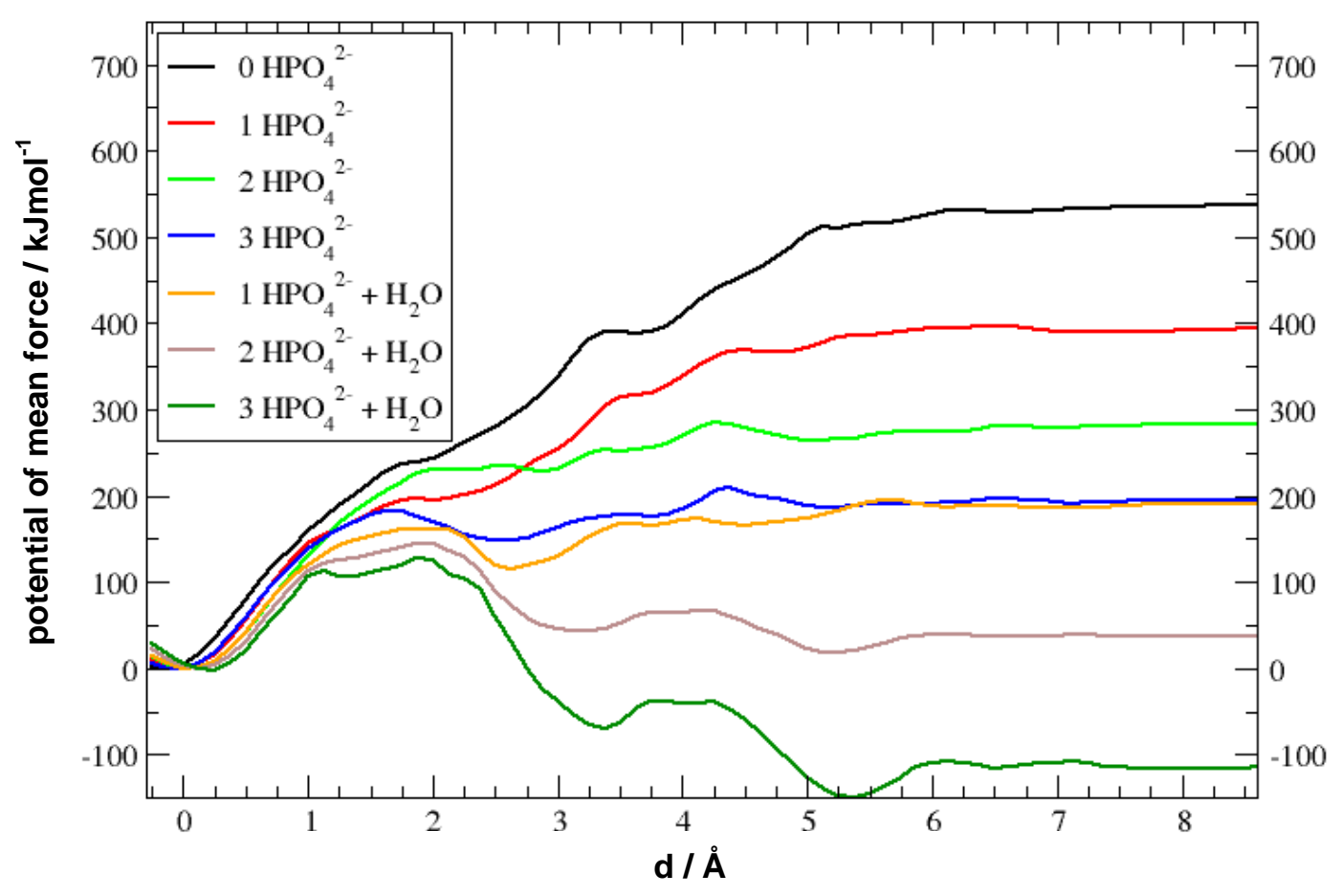

